Supplement of

\title{
Facility-scale inventory of dairy methane emissions in California: impli- cations for mitigation
}

\author{
Alison R. Marklein et al. \\ Correspondence to: Alison R. Marklein (amarklein@ucr.edu)
}

The copyright of individual parts of the supplement might differ from the article licence. 


\section{SUPPLEMENT:}

\section{S1. Supplemental Methods}

\section{$\underline{\text { S1.1 Uncertainty analysis }}$}

\section{S1.1.1 Facility level uncertainty}

$\mathrm{n}$ : We assume that the uncertainty in the cattle populations is $20 \%$, as recommended by the IPCC. For dairies with cattle permits, the water quality board assumes $15 \%$ uncertainty in population (California Regional Water Quality Control Board, 2013). This uncertainty is likely an underestimate, as there are likely dairies in VISTA that are no longer extant, due to the declining dairy industry, and it is possible that there are dairies that exist that are not included in the database. We do not expect the uncertainty to follow a normal distribution; rather there are likely a few dairies where the estimates are far from correct. The data regarding the number of cows are proprietary information that are not consistently reported by any one agency, and the agencies do not communicate with each other. Further, the number of milk cows vary interannually (as they only lactate for part of the year, and are considered dry cows the remainder of the year), and the animals are sold and traded. These factors make this information surprisingly difficult to estimate.

E1: The EPA 2017 reports the $95 \%$ confidence bounds as -11 to $18 \%$ of the mean enteric emissions uncertainty at the national level (US EPA, 2017). We assume this is the same uncertainty as the uncertainty in ef $f_{1}$ at the facility level, as this is the only factor besides the number of cows in this model. We convert $95 \% \mathrm{CI}$ into $\mathrm{SE}$ by assuming that $95 \% \mathrm{CI}=3.92 * \mathrm{SE}$.

E2: Hristov et al. 2017 provides the $95 \%$ confidence bounds as a $\%$ of the mean for the parameters in the model (Hristov et al., 2017). For DMI, The confidence bounds are $34.4-35.1 \%$ for DMI and $38.3-39.0 \%$ for $\mathrm{ef}_{2}$. We convert $95 \% \mathrm{CI}$ into SE by assuming that $95 \% \mathrm{CI}=3.92 * \mathrm{SE}$, resulting in $0.18 \%$ for DMI and 0.20 for $\mathrm{ef}_{2}$.

E3: CARB provides the minimum and maximum of DMI, NDF, and mf (Appuhamy, 2018). We assume the range rule, which assumes a normally distributed population, such that $\mathrm{SD}=(\max -\mathrm{min}) / 4$ and $\mathrm{SE}=$ $\mathrm{SD} / \mathrm{sqrt}(\mathrm{n})$, and calculate SE based on $\mathrm{n}=77$, the number of sources in the literature with methane emissions representative of California dairy cows, as reported in Appuhamy 2018. The range rule works best when data are normally distributed and $\mathrm{n} \sim 30$. Error ranges are also provided for $\mathrm{fDMI}_{\mathrm{DM}} \mathrm{f}_{\mathrm{NDF}}$, and $\mathrm{f}_{\mathrm{mf}}$, which we assume to be standard error.

M1: The IPCC states that the uncertainty range for emissions using regional MCF, Bo, and VS is $20 \%$. We therefore assume $20 \%$ uncertainty in $\mathrm{CH}_{4, \mathrm{~m} 1}$ (Dong et al., 2006).

M2: Hristov et al. (Hristov et al., 2017) report the $95 \%$ confidence bounds for manure management to be $65 \%-63.3 \%$, though their estimate includes swine and poultry in addition to cattle. We convert $95 \% \mathrm{CI}$ into SE by assuming that $95 \% \mathrm{CI}=3.92 * \mathrm{SE}$.

M3: For manure method three, we assess the uncertainty in time on concrete, volatile solid production, and methane conversion factors as described below. We propagate the error using partial derivatives.

Time on concrete: We estimated the standard error for time on concrete for freestall, nonfreestall dairies, and for nonlactating animals from a report that provided time on concrete at four dairies in the Central Valley (Meyer, 2019). We calculated standard error as the standard deviation divided by the square root of the number of samples. For the freestall dairies $(\mathrm{n}=2)$, one dairy had $78.2 \%$ time on concrete and the other dairy had $69.8 \%$ time on concrete. We calculated the mean and standard error of these two measures of time on concrete, which were $(74.0+/-5.9) \%$. For the nonfreestall lanes $(n=2)$, the two dairies had 31.0$37.0 \%$ time on concrete, which is the mean of $(34.0+/-4.4) \%$. For the nonlactating cows, the average time on concrete from the four facilities were $26.5+/-6.5$, based on $23.8,25.1,21.0$, and $35.9 \%$ at the four facilities. 
Volatile solid production: To estimate the standard error in volatile solid production, we calculated the mean and standard error of the VS production by lactating lactating cows and replacement heifers using data from 2000-2012 from the CARB inventory (US EPA, 2017).

Methane Conversion Factor: Owen and Silver 2014 report a field-derived methane conversion factor of $(84+/-44) \%$ (confidence intervals) from a total of 9 observations for lagoon storage and $2.9+/-2.5$ from a total of 4 observations for solid storage (Owen \& Silver, 2014). We convert the confidence intervals into standard errors, and fractional uncertainty by dividing the error by the estimate.

$f_{\text {bed: }}$ We estimate the standard error in the fraction of manure solids that are used as bedding to be $100 \%$, as some dairies may not use any manure solids for bedding, and others may use all manure solids as bedding.

$\mathrm{B}_{0}$ : The IPCC states a $15 \%$ uncertainty in $\mathrm{B}_{0}$; however, a meta-analysis of methane conversion factors from lagoons showed a standard error of 23\% (Miranda et al. 2016).

\section{S1.1.2 Statewide uncertainty}

Because of the large number of dairies, propagating the error throughout the state calculates an improbably small statewide error. Therefore, we use previously published estimates for E1, E2, M1, and M2. We use IPCC recommendations for E3 and M3 (Dong et al., 2006).

E1: The EPA 2017 reports the $95 \%$ confidence bounds as -11 to $18 \%(+/-7.4 \%)$ of the mean enteric emissions uncertainty at the national level (US EPA, 2017). We assume this uncertainty is the same in California as in the national scale. We convert $95 \% \mathrm{CI}$ into SE by assuming that $95 \% \mathrm{CI}=3.92 * \mathrm{SE}$.

E2: Hristov et al. 2017 (Hristov et al., 2017) report the 95\% confidence intervals of average annual enteric emissions from the continental United States to be $15.6-16.9 \%(+/-8.3 \%)$. We assume this uncertainty is the same in California as in the national scale. We convert $95 \% \mathrm{CI}$ into SE by assuming that $95 \% \mathrm{CI}=3.92$ * SE.

E3: The IPCC suggests using $+/-20 \%$ using Tier 2 methodology, which we assume is the uncertainty for our statewide assessment (Dong et al., 2006).

M1: The EPA reports -18 to $20 \%(+/-9.7 \%)$ uncertainty for manure management $\mathrm{CH} 4$ emissions, which we use here (US EPA, 2017). We assume this uncertainty is the same in California as in the national scale. We convert $95 \% \mathrm{CI}$ into SE by assuming that $95 \% \mathrm{CI}=3.92 *$ SE.

M2: Hristov et al. 2017 (Hristov et al., 2017) report the 95\% confidence intervals of average annual manure emissions from the continental United States to be -65.0 to $63.3 \%$ (+/-32.7\%). We assume this uncertainty is the same in California as in the national scale. We convert $95 \% \mathrm{CI}$ into SE by assuming that $95 \% \mathrm{CI}=$ $3.92 * \mathrm{SE}$.

M3: The IPCC suggests using $+/-30 \%$ as confidence intervals using Tier 2 methodology, which we assume is the uncertainty for our statewide assessment (Dong et al., 2006).

103

104 
Table S1. Manure partitioning for method M3. The time on concrete number includes the time in milking parlor. San Joaquin Valley, with air quality data.

\begin{tabular}{|l|l|l|l|l|l|}
\hline MCF & & $\begin{array}{l}\text { SJV: with } \\
\text { freestalls }\end{array}$ & $\begin{array}{l}\text { SJV: No } \\
\text { freestalls }\end{array}$ & North Coast & Southern \\
\hline & $\begin{array}{l}\text { Time in milking } \\
\text { parlor (tomp) }\end{array}$ & 0.125 & 0.125 & 0.125 & 0.125 \\
\hline $\begin{array}{l}\text { Time on concrete } \\
\text { (toc) }\end{array}$ & 0.70 & 0.34 & 0.34 & 0.34 \\
\hline $\mathbf{0 . 0 4}$ & Solid & 1 -toc & 1 -toc & 0 & 0 \\
\hline $\mathbf{0 . 0 1 5}$ & Pasture & 0 & 0 & 1 -toc & 0 \\
\hline $\mathbf{0 . 7 3 1}$ & Lagoon & toc & toc & tomp & toc \\
\hline $\mathbf{0 . 3 2 3}$ & Slurry & 0 & 0 & toc-tomp & 0 \\
\hline $\mathbf{0 . 0 1 5}$ & Drylot & 0 & 0 & 0 & 1 -toc \\
\hline
\end{tabular}

Table S2. Fraction of manure entering each management type for replacement heifers and calves,

\begin{tabular}{|r|r|r|r|}
\hline Management type & M1 & M2 & M3 \\
\hline Daily spread & $10.8 \%$ & $11 \%$ & $0 \%$ \\
\hline Solid storage & $0 \%$ & $0 \%$ & $100 \%$ \\
\hline Liquid slurry & $0.9 \%$ & $1 \%$ & $0 \%$ \\
\hline Anaerobic lagoon & $0 \%$ & $0 \%$ & $0 \%$ \\
\hline Dry lot & $87.4 \%$ & $88 \%$ & $0 \%$ \\
\hline Pasture & $0.9 \%$ & $1 \%$ & $0 \%$ \\
\hline Anaerobic digester & $0 \%$ & $0 \%$ & $0 \%$ \\
\hline
\end{tabular}


121 Table S3. Number of farms and milk cows in database with usda reports and in total database for each 122 county (USDA NASS, 2017).

123

\begin{tabular}{|c|c|c|c|c|}
\hline County & Nfarms_usda & Ncows_usda & nfarms_vista & ncows_vista \\
\hline Butte & 10 & 427 & 3 & 468 \\
\hline Colusa & 4 & 80 & 1 & 8 \\
\hline Del Norte & 7 & 6452 & 8 & 6448 \\
\hline Fresno & 65 & 102796 & 81 & 10279 \\
\hline Glenn & 28 & 15533 & 36 & 1553 \\
\hline Humboldt & 96 & 23894 & 63 & 23877 \\
\hline Imperial & 2 & 0 & 16 & \\
\hline Kern & 41 & 116605 & 53 & 12979 \\
\hline Kings & 101 & 173404 & 153 & $17340 s$ \\
\hline Lassen & 8 & 22 & 2 & 22 \\
\hline Los Angeles & 1 & 0 & 1 & \\
\hline Madera & 34 & 66038 & 46 & 67661 \\
\hline Marin & 31 & 10895 & 26 & 1089 \\
\hline Mendocino & 13 & 1182 & 5 & 1180 \\
\hline Merced & 202 & 272534 & 289 & 272545 \\
\hline Modoc & 2 & 0 & 1 & \\
\hline Monterey & 7 & 1445 & 1 & 1445 \\
\hline Placer & 25 & 946 & 2 & 946 \\
\hline Riverside & 36 & 38033 & 33 & $3804 \mathrm{C}$ \\
\hline Sacramento & 34 & 16027 & 36 & 16026 \\
\hline San Bernardino & 40 & 52554 & 76 & 52592 \\
\hline San Diego & 9 & 4330 & 4 & 4328 \\
\hline San Joaquin & 97 & 106375 & 129 & 106366 \\
\hline San Luis Obispo & 16 & 256 & 1 & 256 \\
\hline San Mateo & 4 & 10 & 1 & 10 \\
\hline Santa Barbara & 3 & 0 & 1 & 1600 \\
\hline Siskiyou & 15 & 1193 & 3 & 119 \\
\hline Solano & 8 & 22 & 2 & 611 \\
\hline Sonoma & 125 & 33059 & 68 & 33048 \\
\hline Stanislaus & 190 & 183496 & 255 & 18346 \\
\hline Sutter & 4 & 5 & 1 & \\
\hline Tehama & 35 & 3249 & 12 & 3253 \\
\hline Tulare & 235 & 500402 & 312 & 500395 \\
\hline Yolo & 4 & 0 & 2 & 105 \\
\hline Yuba & 6 & 0 & 4 & 1417 \\
\hline
\end{tabular}




\section{References}

Appuhamy, R. (2018). CHARACTERIZING CALIFORNIA-SPECIFIC CATTLE FEED RATIONS AND IMPROVE MODELING OF ENTERIC FERMENTATION FOR CALIFORNIA'S GREENHOUSE GAS INVENTORY 2018, 1-41.

California Regional Water Quality Control Board. (2013). Reissued waste discharge requirements general order for existing milk cow dairies, 1-167.

Dong, H., Mangino, J., McAllister, T. A., Hatfield, J. L., Johnson, D. E., Lassey, K. R., et al. (2006). 2006 IPCC Guidelines for National Greenhouse Gas Inventories (pp. 1-87).

Hristov, A. N., Harper, M., Meinen, R., Day, R., Lopes, J., Ott, T., et al. (2017). Discrepancies and Uncertainties in Bottom-up Gridded Inventories of Livestock Methane Emissions for the Contiguous United States. Environmental Science \& Technology, 51(23), 13668-13677. http://doi.org/10.1021/acs.est.7b03332

Meyer, D. (2019). Characterize Physical and Chemical Properties of Manure in California Dairy Systems to Improve Greenhouse Gas Emission Estimates, 1-70.

Owen, J. J., \& Silver, W. L. (2014). Greenhouse gas emissions from dairy manure management: a review of field-based studies. Global Change Biology, 21(2), 550565. http://doi.org/10.1111/gcb.12687

US EPA, O. C. C. D. (2017). Inventory of U.S. Greenhouse Gas Emissions and Sinks: 1990-2015 - Annexes, 1-475.

USDA NASS. (2017). Census of Agriculture, 1-20. Retrieved from www.nass.usda.gov/AgCensus 